\begin{tabular}{|c|l|}
\hline Title & $\begin{array}{l}\text { Photoacoustic spectroscopic analysis of photoinduced change in absorption of titanium(IV) oxide photocatalyst powders } \\
\text { : A novel feasible technique for measurement of defect density }\end{array}$ \\
\hline Author(s) & Murakami, Naoya; Prieto Mahaney, Orlando Omar; Torimotoa, Tsukasa; Ohtani, Bunsho \\
\hline Citation & $\begin{array}{l}\text { Chemical Physics Letters, 426(1-3), 204.208 } \\
\text { https://doi.org/10.1016/.cplett.2006.06.001 }\end{array}$ \\
\hline Issue Date & 2006-07-26 \\
\hline Doc URL & http://hdl.handle.net/2115/14587 \\
\hline Type & article(author version) \\
\hline File Information & CPL.pdf \\
\hline
\end{tabular}

Instructions for use 


\title{
Photoacoustic spectroscopic analysis of photoinduced change in absorption of titanium(IV) oxide photocatalyst powders: A novel feasible technique for measurement of defect density
}

\author{
Naoya Murakami, ${ }^{\mathrm{a}}$ Orlando Omar Prieto Mahaney, ${ }^{\mathrm{a}}$ Tsukasa Torimoto, ${ }^{\mathrm{a}, \mathrm{b}}$ Bunsho Ohtani, ${ }^{\mathrm{a}, \mathrm{b},}$ \\ ${ }^{a}$ Graduate School of Environmental Earth Science, Hokkaido University, Sapporo 060-0810, Japan \\ ${ }^{\mathrm{b}}$ Catalysis Research Center, Hokkaido University, Sapporo 01-0021, Japan \\ Received 19 April 2006; in final form 25 May 2006
}

\begin{abstract}
Photoabsorption properties of titanium(IV) oxide powders were investigated by photoacoustic (PA) spectroscopy. The photoacoustic spectra obtained under steady-state ultraviolet irradiation showed appearance and growth of two kinds of PA signal bands, which were attributable to trivalent titanium species $\left(\mathrm{Ti}^{3+}\right)$ and trapped holes or surface peroxide species. The saturation limit of the PA signal was estimated by analyzing the time course of $\mathrm{Ti}^{3+}$ signals and compared to the density of $\mathrm{Ti}^{3+}$ determined by a photochemical method. The results suggest that the photoacoustic spectroscopic technique is a feasible alternative method for estimation of $\mathrm{Ti}^{3+}$ as an empirical measure of defect density.
\end{abstract}

* Corresponding author. FAX: +81-11-706-9133.

E-mail address: ohtani@cat.hokudai.ac.jp (B. Ohtani). 


\section{Introduction}

Titanium(IV) oxide $\left(\mathrm{TiO}_{2}\right)$ has been one of the attractive functional materials, especially those used as photocatalysts, owing its nontoxicity, availability, superior redox ability and photostability [1,2]. Photocatalytic reactions on $\mathrm{TiO}_{2}$ are known to be induced by excited electrons and positive holes, but most of these species recombine with each other without contributing to the reaction, judging from the reported quantum efficiency of much less than unity. It has been thought that defects trapping these species act as a recombination center, and it is therefore important to study the correlation between defects and photocatalytic activity. However, there are no direct methods, as far as we know, to measure the defect density in powder samples. We have developed a photochemical method to measure the molar amount of trivalent titanium species $\left(\mathrm{Ti}^{3+}\right)$, a trapped electron on surface and bulk titanium atoms, as an empirical measure of the density of crystalline defects in $\mathrm{TiO}_{2}$ samples and its reciprocal relation with photocatalytic activity. We have proposed a linearity of the $\mathrm{Ti}^{3+}$ density with the defect density but with no certified claim that these two species are identical [3]. Electron paramagnetic resonance (EPR) has also been used to measure such species [4-8], though active oxygen species liberated simultaneously may interfere. Spectroscopy is an alternative way for investigation on the dynamics of electrons and positive holes, and ultrafast spectroscopy under various conditions has been reported [9-13]. In those spectroscopic studies, diffuse reflectance (DR) spectroscopy has been frequently employed to estimate absorption of powder samples, but sometimes scattering and reflection cause difficulty in accurate measurement of photoabsorption [14]. Photoacoustic spectroscopy (PAS) [15], one of the photothermal spectroscopic techniques, is applicable to even strongly scattering solid materials, because photoabsorption is detected by photothermal waves, i.e., acoustic sounds generated by relaxation of the photoexcited state, e.g., recombination of an electron-hole pair in photocatalysts. Moreover, photoacoustic (PA) detection is more sensitive than conventional optical methods, and even small absorption such as that due to a small number of defects can 
be detected. Results of PAS analyses of $\mathrm{TiO}_{2}$ powders [16,17] and photochromism under ultraviolet (UV) irradiation [18] have been reported, but no systematic studies for photocatalyst powders have so far been performed.

In this study we investigated the photoabsorption properties of $\mathrm{TiO}_{2}$ samples with various chemical and physical properties by PAS and detected the absorption attributable to photoproduced $\mathrm{Ti}^{3+}$ species by developing a technique of in situ UV illumination. We also made time-resolved measurements of the generation and extinction of $\mathrm{Ti}^{3+}$ species to estimate the intrinsic defect density in the samples, which was compared with that measured by the above-mentioned photochemical method.

\section{Experimental}

Twenty-two $\mathrm{TiO}_{2}$ powder samples (Merck, Ishihara CR-EL, Hombikat UV-100, Wako amorphous, Degussa P-25 and Showa Titanium ST series) and the reference catalysts supplied from the Catalysis Society of Japan (JRC-TIO series) were used. Their crystal structures were determined by X-ray diffraction analysis, and specific surface areas were measured by nitrogen adsorption on the basis of the Brunauer-Emmett-Teller equation.

A home-made PA cell with an aluminum body (inside volume, $\approx 0.5 \mathrm{~cm}^{3}$ ) and a quartz-glass window, transparent over the range of measurements, 300-600 nm, was used. The cell was suspended with rubber bands to minimize vibrational noise during the measurement. A powder sample was placed in the cell, and PA spectra were measured at room temperature in air or under nitrogen atmosphere. Monochromatic light $(\approx 0.2 \mathrm{~mW} \mathrm{~cm})^{-2}$ was extracted from the output of a 300-W Xe lamp (Eagle LX300) using a monochromator (Jasco CT-101T) and modulated by a light chopper at $80 \mathrm{~Hz}$. The PA signal acquired by a condenser microphone buried in the cell was amplified and monitored by a digital lock-in amplifier (NF LI5640). In addition to this ordinary single-beam (SB) measurement, measurements with simultaneous continuous irradiation, i.e., double-beam (DB) measurement, 
were also carried out. A more intense light beam from a Xe lamp passing through a UV-D33S optical filter (transmitting radiation of $300-400 \mathrm{~nm}$, Asahi Techno Glass) was used as a continuous UV-light source $\left(8.2 \mathrm{~mW} \mathrm{~cm}^{-2}\right)$. The PA signal was normalized using carbon black powder as a reference to compensate wavelength-dependent light intensity.

A flow-type PA cell in which the atmosphere was controlled by the flow of a given gas, e.g., methanol-vapor containing nitrogen, was used for time-resolved measurements. The light source was a light-emitting diode (Nichia NSPG500S) centered at $520 \mathrm{~nm}$, and its output intensity was modulated by a digital function generator (NF DF1905). Other settings were almost the same as those used with the sealed cell.

The amount of $\mathrm{Ti}^{3+}$ was measured by photoinduced electron accumulation in $\mathrm{TiO}_{2}$ suspended in deaerated aqueous solutions containing sacrificial hole scavengers and subsequent reduction of methylviologen to its cation radical [3].

\section{Results and discussion}

\subsection{SB measurements}

Figure 1 (a) shows SB-PA spectra of typical samples. It is known that PA intensity is in principle proportional to the absorption coefficient, but it is saturated in the range of strong absorption, as seen by a plateau below $350 \mathrm{~nm}$, because the PA signal depends on optical as well as thermal properties [13]. Therefore, a comparison of the absolute PA intensity of powder samples requires (usually unknown) knowledge of thermal properties. Figure 1(b) shows PA spectra normalized at maximum wavelength. These spectra differ from one another reflecting their crystal structures: rutile, anatase or amorphous. As observed in the normalized spectra for the samples of rutile, rutile-anatase mixture, anatase, and amorphous, on-set wavelengths shift from $\approx 420 \mathrm{~nm}$ to $\approx 380 \mathrm{~nm}$. This shift almost coincides with that observed in the DR spectra (data not shown) for these samples, reflecting their band gaps: 3.0 $\mathrm{eV}(413 \mathrm{~nm})$ for rutile, $3.2 \mathrm{eV}(388 \mathrm{~nm})$ for anatase and higher for amorphous. 


\subsection{SB and DB measurements}

Simultaneous continuous UV-irradiation in the DB measurements induced dynamic modification of PA spectral behavior that depended strongly on the samples. The measured samples can be categorized into two groups from this behavior.

3.2.1. Type 1 samples. The first group (Type 1) showed an upward shift of the signal above $380 \mathrm{~nm}$ under UV irradiation and recovery in the dark. Figure 2 shows the SB- and DB-PA spectra of representative Type 1 samples (JRC-TIO-1) in a logarithmic scale to emphasize the intensity change. These samples showed no appreciable differences in the SB measurements but an upward shift in the DB measurements. Sub-band gap irradiation induced no upward shift in the DB measurements, and the upward shift was increased by purging of air with nitrogen; this suggests that photoexcited electrons, but not positive holes, induce this shift without the retardation by oxygen in air. Therefore, this DB-PA signal is attributable to the $\mathrm{Ti}^{3+}$ species produced via electron accumulation in $\mathrm{TiO}_{2}$ as a counterpart of hole consumption, presumably by residual organic compounds. Similar absorption appearing under UV irradiation [18,19] and anodic polarization of film [20] has been reported. Since the accumulated electrons can be transferred to oxygen adsorbed on the surface as was observed in the dark, the steady-state intensity of the $\mathrm{Ti}^{3+}$ band depends on the continuous-light intensity. This is the reason why no $\mathrm{Ti}^{3+}$ band appears in the SB measurements with less intense monochromatic illumination. Among the Type 1 samples, JRC-TIO-6 showed a slightly different shape of the DB-PA spectrum with intensity decreasing with the wavelength; the other samples exhibited almost horizontal spectra like JRC-TIO-1 in Fig. 2. The characteristic behavior of JRC-TIO-6 is discussed in 3.2.3.

3.2.2. Type 2 samples. The second group (Type 2) includes samples of relatively large specific surface area (>100 $\left.\mathrm{m}^{2} \mathrm{~g}^{-1}\right)$, e.g., Hombikat UV-100, JRC-TIO-7 - 10, 12 and Wako amorphous samples. They showed a PA signal increase at $380-500 \mathrm{~nm}$ with repeated SB measurements, as shown in Fig. 3(a). The growth of this signal was observed in the SB scan 
below $400 \mathrm{~nm}$, indicating that band-gap excitation induced the growth. This band was also observed in subsequent DB measurements but decreased in repeated DB runs. A similar PA band was observed for some platinized Type 1 samples. These observations suggest that electrons were scavenged by an acceptor, such as oxygen or platinum, and that positive holes left behind were trapped in certain states, being consistent with the assignment of this band to trapped holes or their derivatives. A similar behavior was observed when the cell was purged with nitrogen blow, presumably due to electron scavenging by remaining tightly bound oxygen. A similar assignment of a transient absorption peak at $\approx 430 \mathrm{~nm}$ has been reported [9]. A possible structure of the trapped hole is surface-bounded hydroxyl radicals, though we do not yet have evidence supporting this.

Another possible assignment of the $380-500 \mathrm{~nm}$ signal is surface peroxy species, since it was reported that treatment of $\mathrm{TiO}_{2}$ with aqueous hydrogen peroxide $\left(\mathrm{H}_{2} \mathrm{O}_{2}\right)$ led to absorption at $350-500 \mathrm{~nm}[21,22] . \mathrm{H}_{2} \mathrm{O}_{2}$ can be produced by reaction of photoexcited electrons with molecular oxygen via superoxide anion $\left(\mathrm{O}_{2}{ }^{-}\right)$[23,24], and EPR studies have suggested the liberation of peroxide species in the presence of oxygen [6], though we have no information on the origin. Anatase $\mathrm{TiO}_{2}$ samples of large specific surface area have been shown to have large amounts of hydroxyl groups and physisorbed water through studies of infrared spectroscopy [6, 25], thermogravimetry [5, 26, 27] and ${ }^{1} \mathrm{H}$ NMR [28], and these species on Type 2 samples might participate in the hole trapping and/or peroxy species productions.

In DB measurements, the signal decreased in the wavelength of $380-500 \mathrm{~nm}$ but increased in the wavelength of 500-600 nm, presumably due to enhanced rate of production of $\mathrm{Ti}^{3+}$ by excess electrons, which might also reduce trapped holes and peroxy species. It is also notable that the continuous UV irradiation in DB measurements can excite the former band but not the latter; the $380-500 \mathrm{~nm}$ band might be diminished by the photoreaction of itself under intense light-irradiation. The behavior of spectral change between (1) and (4) in Fig. 3(a) was similar to that of Type 1 samples, and the increase in this range $(500-600 \mathrm{~nm})$ was therefore 
thought to be mainly due to the formation of $\mathrm{Ti}^{3+}$ as was observed for Type 1 samples in DB measurements.

3.2.3. Type 2 samples in the presence of surface-adsorbed methanol. Figure 3 (b) shows the DB-PA spectra of JRC-TIO-12 with methanol adsorbed by means of methanol-vapor exposure. The PA band in the wavelength of 380-500 nm was significantly weaker than that observed in the absence of methanol. This behavior resembled to some extent that of Type 1 samples in the absence of methanol; the trapped holes were decreased by reaction of original and/or trapped holes with methanol, resulting in accelerated production of $\mathrm{Ti}^{3+}$. The DB-PA spectrum of JRC-TIO-12 (Fig. 3 (b)-(4)) with adsorbed methanol was similar to that of JRC-TIO-6 rather than that of typical type-1 samples. This indicates that a similar phenomenon, hole trapping or peroxy species formation, might occur in JRC-TIO-6.

\subsection{Time-resolved measurements}

Time-resolved measurements were also conducted in the presence of hole scavengers in air or under nitrogen. Because the PA band at $380-500 \mathrm{~nm}$ includes the signal due to trapped holes or peroxy species formation, modulated light of fixed wavelength at $520 \mathrm{~nm}$ was used to detect only the absorption attributable to $\mathrm{Ti}^{3+}$. With simultaneous $\mathrm{UV}$ irradiation in $\mathrm{DB}$ measurements, the PA intensity increased but showed saturation over a period of $1 \mathrm{~h}$; the rate of increase depended on the samples. In order to estimate the saturation limit $\left(I_{520}\right)$, corresponding to the maximum yield of $\mathrm{Ti}^{3+}$ in each sample, the time-course curve of the PA intensity at $520 \mathrm{~nm}$ was fitted, for convenience, to a set of three exponential functions $I$ (Eq. (1)) and $I_{520}$ was obtained from their saturated values (Eq. (2)).

$$
\begin{aligned}
& I(t)=\sum_{i=1}^{3} a_{i}\left[1-\exp \left(-t / \tau_{i}\right)\right] \\
& I_{520}=I(t=\infty)=\sum_{i=1}^{3} a_{i}
\end{aligned}
$$

Figure 4 shows the correlation of $I_{520}$ measured under nitrogen atmosphere with the density of $\mathrm{Ti}^{3+}$ measured photochemically [3]. The reported density of $\mathrm{Ti}^{3+}$ for Merck, CR-EL, 
Hombikat UV-100, Degussa P-25 and JRC-TIO-1-5 was used [3]. The $I_{520}$ values of both Type 1 and 2 samples are nearly proportional to the $\mathrm{Ti}^{3+}$ density. This suggests that the assignment of the PA signal to $\mathrm{Ti}^{3+}$ is reasonable. The only exception is JRC-TIO-6, which shows a different response, as described in 3.2.2.

In comparison with the photochemical method, the present PAS technique has several advantages: (1) The time required is much shorter than the photochemical method, which needed more than 1 day. (2) No redox reagent (methylviologen) is used. (3) The samples can be kept dry and can be recovered. When the measurement for Type 2 samples was carried out in the presence of oxygen, $I_{520}$ was much smaller and the corresponding plots were thereby deviated from the linear master line. This indicates that Type 2 samples are relatively sensitive to ambient oxygen and that the $\mathrm{Ti}^{3+}$ species on those samples are unstable in air.

\section{Conclusion}

We have shown that the PAS measurement under simultaneous continuous UV-irradiation, enables the detection of intermediate species, $\mathrm{Ti}^{3+}$ and trapped holes or surface peroxy species, on a variety of $\mathrm{TiO}_{2}$ samples. The samples can be categorized into two types, either giving mostly $\mathrm{Ti}^{3+}$ and trapped holes or peroxy species in the DB measurements. Analyses of the time course of $\mathrm{Ti}^{3+}$ signal appearing in nitrogen in the presence of surface-adsorbed methanol have enabled estimation of the saturation limit of $\mathrm{Ti}^{3+}$ accumulation, regardless of the sample type.

\section{Acknowledgments}

The authors gratefully acknowledge Professor Taro Toyoda (The university of Electro-Communications) for his help in the design of PAS setups. This work was supported by a Grant-in-Aid for Scientific Research on Priority Areas (417) from the Ministry of Education, Culture, Sports, Science and Technology (MEXT) of Japan. 


\section{References}

[1] A. Mills, S.L. Hunte, J. Photochem. Photobiol. A: Chem. 108 (1997) 1.

[2] O. Carp, C.L. Huisman, A. Reller, Prog. Solid State Chem. 32 (2004) 33.

[3] S. Ikeda, N. Sugiyama, S. Murakami, H. Kominami, Y. Kera, H. Noguchi, K. Uosaki, T. Torimoto, B. Ohtani Phys. Chem. Chem. Phys. 5 (2003) 778.

[4] R.F. Howe, M. Gratzel, J. Phys. Chem. 91 (1987) 3906.

[5] Y. Nakaoka, Y. Nosaka, J. Photochem. Photobiol. A 110 (1997) 299.

[6] J.M. Coronado, A.J. Maria, J.C. Conesa, K.L. Yeung, V. Augugliaro, J. Soria, Langumuir $17(2001) 5368$.

[7] T. Berger, M. Sterrer, O. Diwald, E. Knozinger, D. Panayotov, T.L. Thompson, T. Yates, Jr., J. Phys. Chem. B 109 (2005) 6061.

[8] Y. Nosaka, M. Kishimoto, J. Nishino, J Phys. Chem. B, 102 (1998) 10279.

[9] D. Bahnemann, A. Henglein, L. Spanhel, Faraday Discuss. Chem. Soc. 78 (1984) 151.

[10] D. Bahnemann, A. Henglein, J. Lili, L. Spanhel, J. Phys. Chem. 88 (1984) 709.

[11] B. Ohtani, R.M. Bowman, D.P. Colombo Jr., H. Kominami, H. Noguchi, K. Uosaki, Chem. Lett. 7 (1998) 579.

[12] A. Yamakata, T. Ishibashi, H. Ohnishi, J. Molec. Catal. A: Chem. 199 (2003) 85.

[13] T. Yoshihara, R. Katoh, A. Furube, Y. Tamaki, M. Murai, K. Hara, S. Murata, H. Arakawa, M. Tachiya J. Phys. Chem. B 108 (2004) 3817.

[14] W.N. Delgass, G.L. Haller, R. Kellerman, J.H. Lunsford, Spectroscopy in Heterogeneous Catalysis, Academic, New York, 1966.

[15] A. Rosencwaig, A. Gersho, J. Appl. Phys. 47 (1976) 64.

[16] T. Toyoda, H. Kawano, Q. Shen, A. Kotera, A. Ohmori Jpn. J. Appl. Phys. 39 (2000) 3160.

[17] T. Toyoda, R. Taira, Q. Shen, M. Ohmori, Jpn. J. Appl. Phys. 40 (2001) 3587.

[18] J.G. Highfield, M. Gratzel, J. Phys. Chem. 92 (1988) 464. 
[19] A.N. Shultz, W. J.ang, W.M. Hetherington III, D.R. Baer, L. Wang, M.H. Engelhard, Surf. Sci. 339 (1995) 114.

[20] T. Toyoda, M. Hayashi, Rev. Sci. Instrum. 74 (2003) 297.

[21] A.H. Boonstra, C.A.H.A. Mutsaers, J. Phys. Chem. 79 (1975) 1940.

[22] G. Munuera, A.R. Gonzalez-Elipe, A. Fernadez, P. Malet, J.P. Espinos, J Chem. Soc. Faraday Trans. 185 (1989) 1279.

[23] C. Kormann, D.W. Bahnemann, M. Hoffmann, Environ. Sci. Technol. 22 (1988)798.

[24] A.J. Hoffman, E.R. Carraway, M.R. Hoffmann, Environ. Sci. Technol. 28 (1994) 776.

[25] H. Jensen, A. Soloviev, Z. Li, E.G. Sogaard, Appl. Surf. Sci. 246 (2005) 239.

[26] T. Hirakawa, Y. Nakaoka, J. Nishino, Y. Nosaka, J. Phys. Chem. B 103 (1999) 4399.

[27] T. Hirakawa, H. Kominami, B. Ohtani, Y. Nosaka, J. Phys. Chem. B 105 (2001) 6993.

[28] A. Nosaka, T. Fujiwara, H. Yagi, H. Akutsu, Y. Nosaka, J. Phys. Chem. B 108 (2004) 9121-9125. 


\section{Figure Captions}

Fig. 1. SB-PA spectra of CR-EL $\{\mathrm{R}\}(\bullet)$, Degussa P-25 $\{\mathrm{A} / \mathrm{R}\}(\mathrm{O}), \mathrm{TIO}-1\{\mathrm{~A}\}(\mathbf{\bullet})$, JRC-TIO-12 $\{\mathrm{A}\}(\square)$, and Wako $\{$ amorphous $\}(\mathbf{\Delta})$. A and R in braces denote crystal structures, anatase or rutile. Measurements were performed in the ambient air. Each measurement required $\approx 1 \mathrm{~h}$.

Fig. 2. PA spectra of JRC-TIO-1. (1)-(3): repetition (without interval between the measurements) of SB measurements, (4): final-state spectrum by repetition of DB measurements in the ambient air. Each measurement required $\approx 1 \mathrm{~h}$.

Fig. 3. (a) PA spectra of JRC-TIO-12. (1): first SB measurement, (2): final-state spectrum by repetition of SB measurements, (3): first DB measurement after (2), (4): final-state spectrum by repetition of DB measurements.

(b) PA spectra of JRC-TIO-12 with adsorbed methanol. (1): first SB measurement, (2): final-state spectrum by repetition of SB measurements, (3): first DB measurement after (2), (4): final-state spectrum by repetition of DB measurements. PA spectra of JRC-TIO-12 without adsorbed methanol. (A): first SB measurement, (B): final-state spectrum by repetition of SB measurements. The conditions for measurements were identical to those for Fig. 2.

Fig. 4. Relation between the saturation limit of PA intensity $I_{520}$ and amount of $\mathrm{Ti}^{3+}$. Mainly

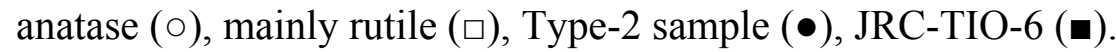


Figures

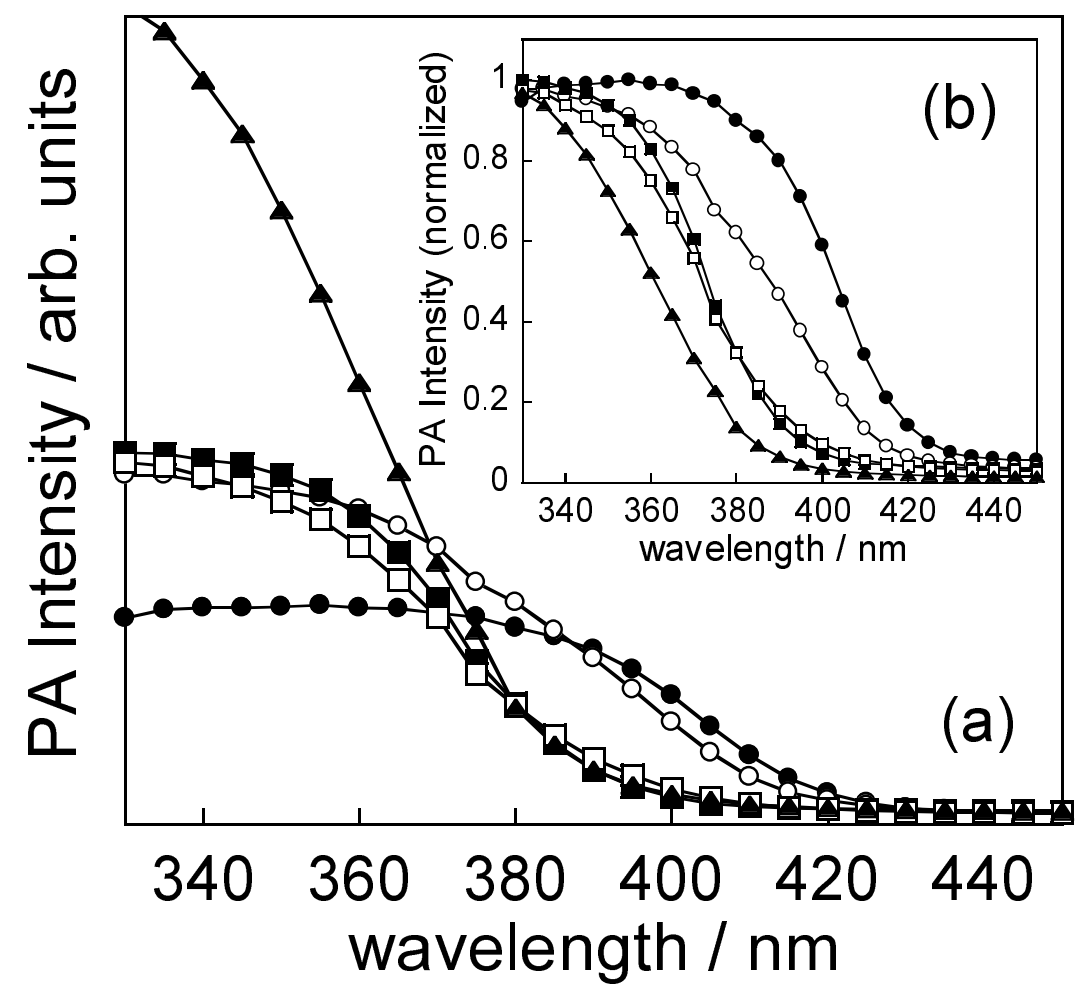

Figure 1 


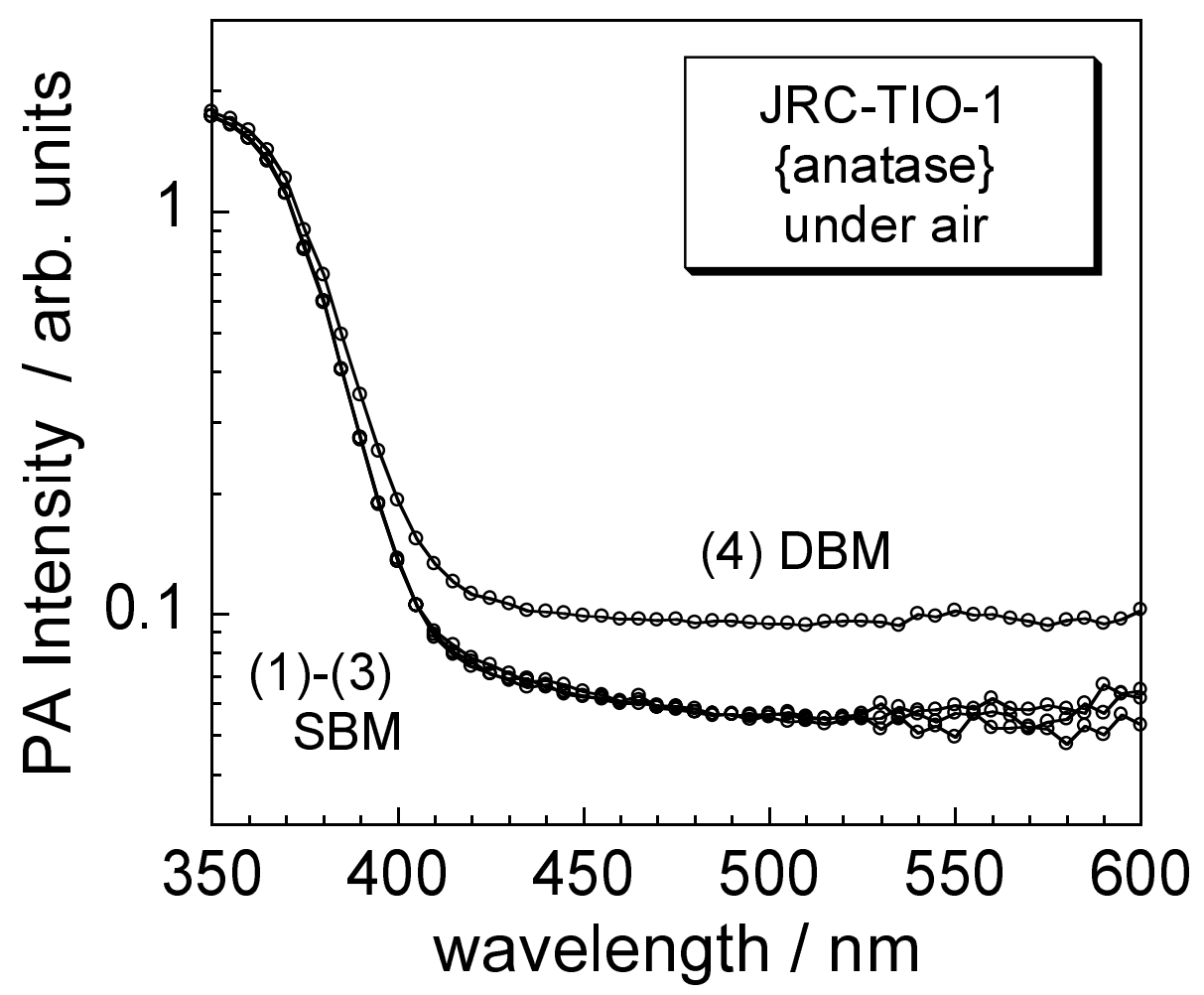

Figure 2 

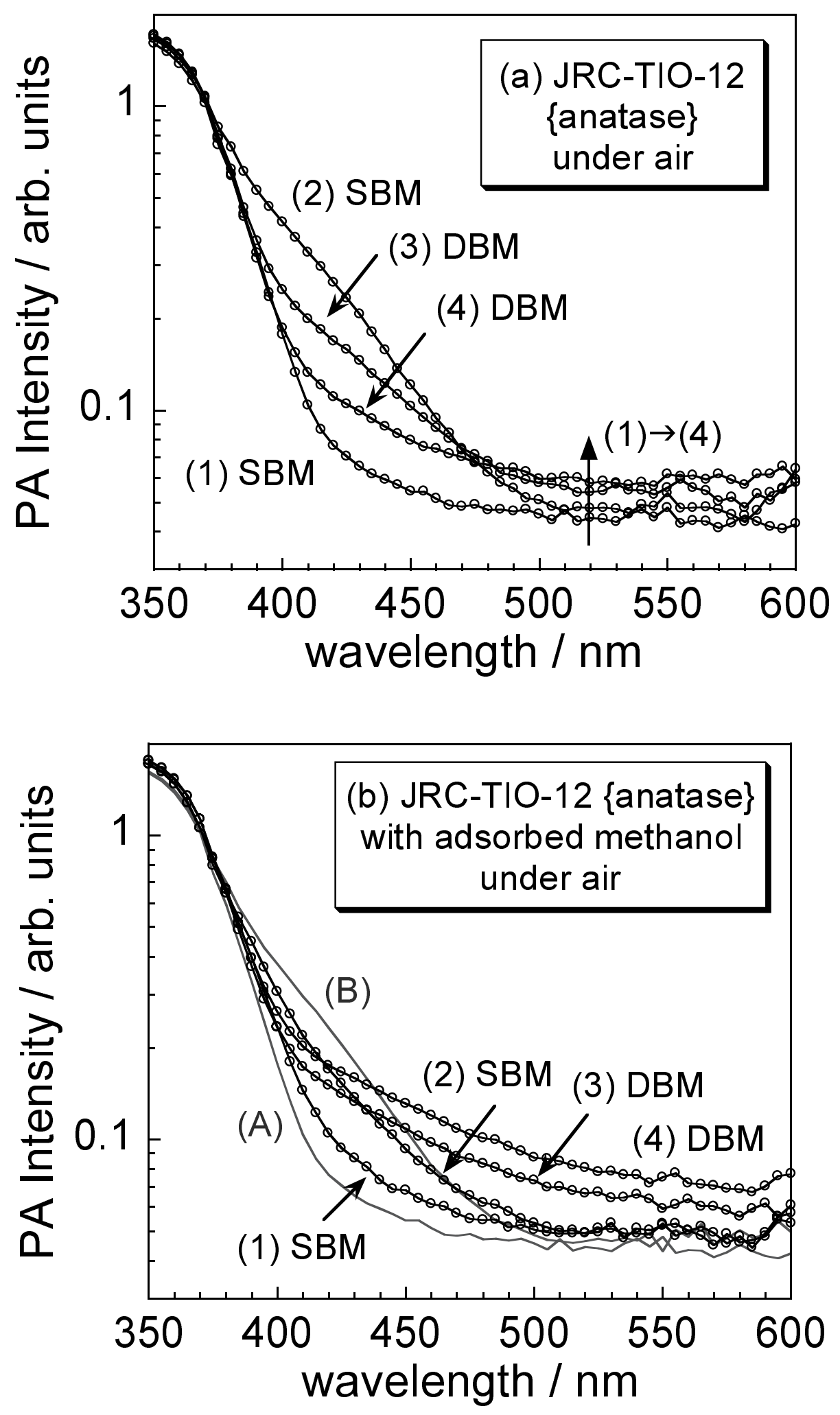

Figure 3 


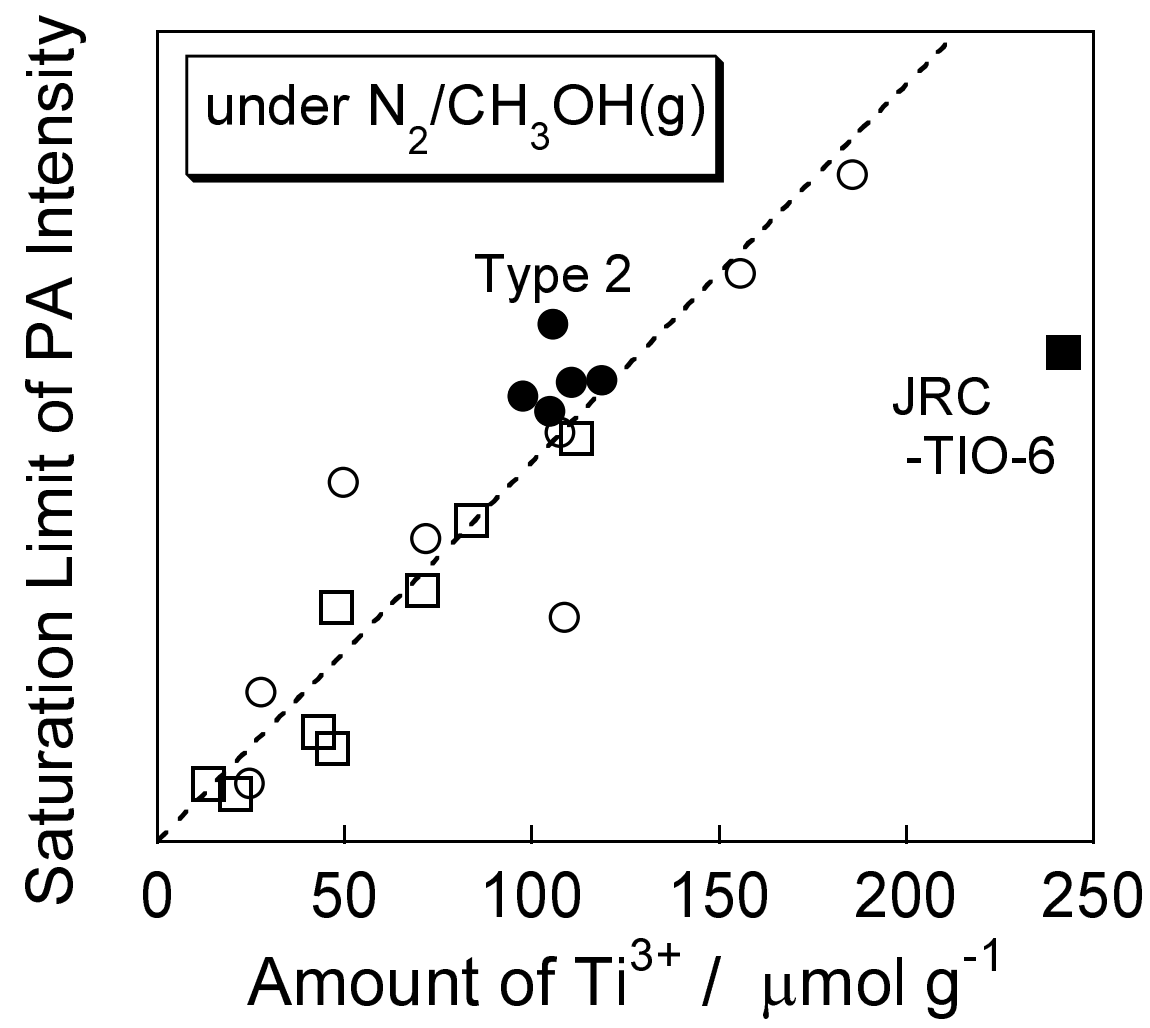

Figure 4 


\section{Graphical Abstract}

Photoabsorption properties of more than 20 titanium(IV) oxide powders were investigated by photoacoustic (PA) spectroscopy. The photoacoustic spectra obtained under steady-state ultraviolet irradiation showed appearance and growth of two kinds of PA signal bands, which were attributable to trivalent titanium species $\left(\mathrm{Ti}^{3+}\right)$ and trapped holes or surface peroxide species.

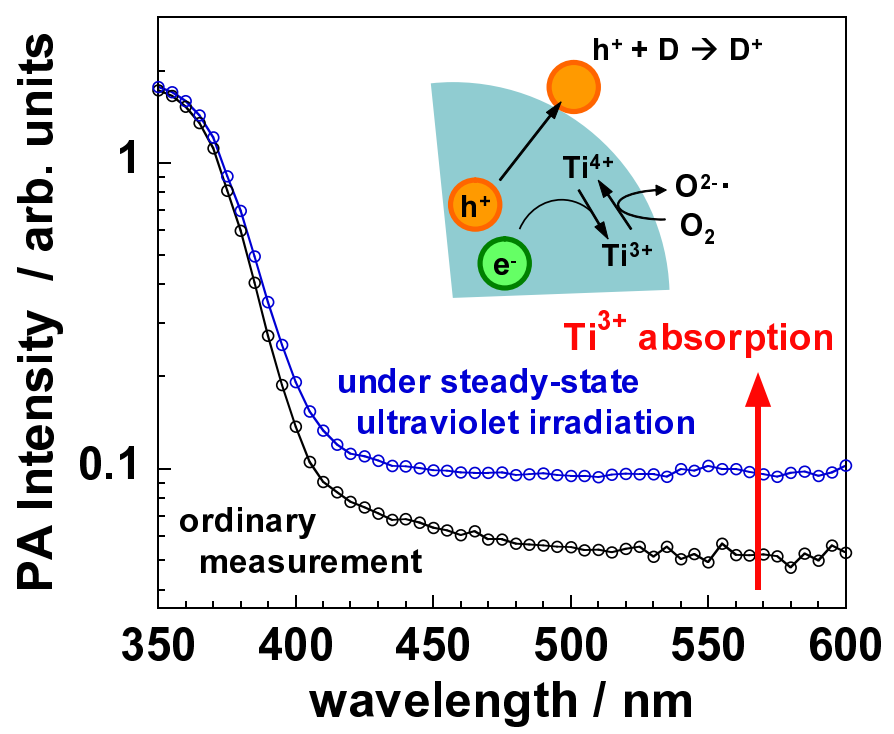

